\title{
Intergenerational Learning Through Community-Based Internships: A Case Study of Grounding Roots' Garden Groups
}

Illana C. Livstrom

University of Minnesota, USA

Gillian H. Roehrig

University of Minnesota, USA

Amy R. Smith

University of Minnesota, USA

Recommended Citation:

Livstrom, I. C., Roehrig, G. H., \& Smith, A. R. (2020). Intergenerational learning through community-based internships: A case study of grounding roots' garden groups. International Journal of Research on ServiceLearning and Community Engagement, 8(1), Article 12. https://doi.org/10.37333/001c.18737 


\title{
Intergenerational Learning Through Community-Based Internships: A Case Study of Grounding Root's Garden Groups
}

\author{
Illana C. Livstrom \\ Gillian H. Roehrig \\ Amy R. Smith \\ University of Minnesota (USA)
}

\begin{abstract}
This research employed a single-case design to examine an urban agricultural internship program called Grounding Roots, which brings together youth interns, and undergraduate and community elder mentors, in intergenerational garden groups. This research question guided the study: How, if at all, can communitybased education through internships support youth who are marginalized in traditional educational environments? Findings highlight holistic educational opportunities found in community-based spaces that connect learning to young people's communities and lives, particularly for youth of marginalized identities. The Grounding Roots program supported youth in multidimensional learning and identity development. The research highlighted important elements of programs to support youth, including having assets recognized and leveraged; building confidence, leadership identities, and diverse relationships; and connecting with the greater community. Further, this research brings attention to the value of intergenerational mentoring and work, diversity in learning communities, and work-based (internship) learning.
\end{abstract}

Keywords: community-based education, diversity, identity, mentors, work-based learning, youth

\section{Aprendizaje intergeneracional a través de prácticas (pasantías) comunitarias: Estudio de caso de los grupos agrícolas Grounding Roots}

Esta investigación empleó un diseño de caso único para examinar un programa de prácticas (o pasantías) agrícolas urbanas llamado Grounding Roots. El programa reúne en grupos agrícolas intergeneracionales a jóvenes en prácticas con mentores comunitarios y de estudiantes de pregrado. La cuestión central del estudio fue: ¿Cómo puede la educación basada en la comunidad a través de prácticas, si es que lo hace, apoyar a los jóvenes marginados de los entornos educativos tradicionales? Los hallazgos de esta investigación destacan las oportunidades educativas integrales que ofrecen los espacios comunitarios al conectar el aprendizaje con las comunidades y vidas de los jóvenes, en particular en el caso de jóvenes con identidades marginalizadas. El programa Grounding Roots sirvió a los jóvenes en un aprendizaje multidimensional y en el desarrollo de su identidad. La investigación destacó algunos elementos importantes de los programas de apoyo a la juventud, tales como el reconocimiento y aprovechamiento de los activos; la construcción de confianza, de identidades de liderazgo y de relaciones de diversidad; y la conexión con la comunidad en general. Por último, esta investigación también revela el valor de los mentores y del trabajo intergeneracional, de la diversidad en las comunidades de aprendizaje, así como el valor del aprendizaje basado en el empleo (pasantías).

Palabras clave: educación basada en la comunidad, diversidad, identidad, mentores, aprendizaje basado en el empleo, juventud

Editors' Note: Translation by Beatriz Calvo-Peña Department of English and Foreign Languages Barry University, USA 
Communities of color and low-socioeconomic status are disproportionately impacted by food, energy, and water insecurity. Additionally, these communities have been historically left out of environmental movements and policy-making. Thus, it is particularly important to involve youth of marginalized identities in addressing grand challenges related to food, energy, and water insecurity, helping them to develop interdisciplinary thinking and problem-solving skills, and the ability to work collaboratively. However, school environments rarely align with natural learning processes. In school, learning is symbolic, abstract, and often disconnected from students' sociocultural and sociohistorical backgrounds and experiences (Buxton, 2010; Ladson-Billings, 2014). Students of color often view school as having little relevance to their lives and futures (Nieto, 1994). Conversely, "when young people are given the chance to direct their energy and intelligence to the life of their community, more than social capital and mutuality are strengthened; they are also able to make real contributions to everyone's welfare" (Smith \& Sobel, 2014, p. 98).

Community-based education (CBE) contextualizes learning, addressing real-world issues in socioculturally relevant ways that allow youth to contribute to their lives and communities. CBE connects students' home, community, and school lives; links learning to the real world; supports students to coconstruct knowledge through interaction; and allows students to contribute as citizens and stewards (Melaville et al., 2006). Research suggests that CBE can support youth in developing critical civic praxis (Ginwright \& Cammarota, 2007); developing agency (Calabrese Barton \& Tan, 2010); and resisting and disrupting deficit-oriented discourses (Baldridge, 2014).

However, research has not assessed the value of community-based internships in providing contextualized learning opportunities, nor the role of intergenerational mentorship and multicultural teams in such spaces. Our work explores these elements in a community-based space to support youth of marginalized identities. Specifically, this research takes place within the context of an urban agricultural internship program called Grounding Roots (GR), which brings together youth interns, and university students and community elders as mentors, in intergenerational garden groups. The following research question guided the study: How, if at all, can community-based education through internships support youth who are marginalized in traditional educational environments?

\section{Literature Review}

In contrast to formal education, $\mathrm{CBE}$ is grounded in local phenomena and epistemologies, with holistic priorities of nurturing young people mentally, emotionally, socially, and emotionally (Smith \& Sobel, 2014). CBE draws on critical pedagogy, problem-based learning, and environmental education to ground learning in local environmental and cultural phenomena connected to students' lived experiences (Smith \& Sobel, 2014; Gruenewald, 2003). Starting from the local, CBE makes the abstract concrete and relevant. The local is experientially situated and transdisciplinary, and can center ecological, environmental, social, or cultural phenomena (Smith \& Sobel, 2014; Gruenewald, 2003). CBE reconceptualizes youth as agents of change who can make valuable contributions to the world and their communities, thus providing students with purpose and responsibility, which is particularly transformational for marginalized youth (Paris \& Winn, 2013; Smith \& Sobel, 2014).

CBE has been critical in serving youth of marginalized identities, humanizing youth where traditional spaces have devalued and pushed them out (Baldridge, 2014; Paris \& Winn, 2013). CBE scholars highlight the counterstories that youth and their communities are actively creating, actively resisting and disrupting deficit-oriented discourse (e.g. Baldridge, 2014; Calabrese Barton \& Tan, 2010; Kwon, 2014). These spaces often serve as sites of resistance and transformation of educational inequalities (Baldridge et al., 2017). In resisting deficit-oriented narratives and creating alternative narratives, CBE supports positive racial and ethnic identity development in youth with identities marginalized. For example, Ginwright and Cammarota (2007) found that community-based organizations can support Latinx and African-American youth in critical civic praxis. Their research highlighted multiple forms of engagement, including youth organizing, civic participation, arts activism, volunteer work that provided social capital support in social networks, intergenerational relationships, and collective action. Similarly, Calabrese 
Barton and Tan (2010) explored a community-based science program that promoted the development of agency for youth as community science experts. They have argued that CBE can provide a space for horizontalization of power, authentic learning, and identity negotiation where marginalized youth have power and position not afforded in traditional spaces.

Without care, CBE spaces can reproduce neoliberal agendas that negatively impact all educational institutions, particularly detrimental to youth of color and low-income status (Baldridge et al., 2017). Many CBE programs are held to the same oppressive academic standards as traditional schools and forced to change their own missions and values to meet requirements of funding sources (Baldridge et al., 2017). Others have criticized CBE programs for containing youth and keeping them complacent (Sukarieh \& Tannock, 2011). Even more concerning, scholars have suggested that CBE programs can operate as programs of social control, trying to fix youth or force conformity to hegemonic norms (Kwon, 2014; Sukarieh \& Tannock, 2011).

\section{Theoretical Framework}

This work views learning as social and cultural processes (e.g. Lave \& Wenger, 1991; Nasir et al., 2006). Learning in most out-of-school spaces is a collective process that occurs in communities through participation, guidance, and apprenticeship. Communities share common goals, processes, and outcomes, and they take on cognitive and physical work together. In the process, learners become skilled and knowledgeable in social and cultural practices that are essential to the community. Dewey (1938) advocated a strong connection between learning and life, and indirect education that was child centered. $\mathrm{He}$ argued that young people have the ability to self-educate, if they are free to follow their natural spirits and interests. From these perspectives, all members of the community are creating, rather than passively receiving (see Freire, 1970). Calabrese Barton and Tan (2010) stated, "Learning is less about practicing the routines of knowledgeable others than it is about recreating those practices in socially and culturally situated ways that confer on one more (or less) agency with which to participate across communities" (pp. 190-191).

Situated learning theory posits that young people learn best in the context of real-world problems, drawing upon all knowledge necessary for the particular context. According to Lave and Wenger (1991), learning and knowing are bound to social, community, cultural, and place-based contexts, and education needs to be situated within and driven by these contexts. Putnam and Borko (2000) argued that situated cognition rests on two main assumptions: (1) cognition is social, multidirectional, and created by the diverse skills and expertise that learners bring to the community and (2) cognition is distributed, occurring across contexts and members of a community. Learning is grounded in communities of practice, which share common goals. Members collaborate and share expertise and leadership to meet these goals. Communities of practice bring people together, in social interaction and joint construction of knowledge and meaning (Lave \& Wenger, 1991).

The construction and reconstruction of the community occurs through these communities of practice, depending on the transfer of knowledge and skills from generation to generation. Learners are integrated into a community of practice through legitimate peripheral participation (Lave \& Wenger, 1991). Learners start out at the periphery of the community, absorbing the learning community and learning from experts. Through guided practice, they learn, grow, and move toward the center of the learning community, where they share expertise and leadership (Lave \& Wenger, 1991). The production and reproduction of knowledge and skills within the community act upon and are acted upon by greater sociopolitical and historical conditions, and always tied up in power relations. In contrast to traditional educational spaces, where power structures are vertical, students are taught to be conformists to dominant structures, and students are viewed as recipients of knowledge rather than creators (see Freire, 1970). 


\section{Context}

Grounding Roots (GR) is a community-driven collaboration between an urban community and local university. Through intergenerational mentorship and urban agriculture, GR works to advance environmental, social, and racial justice in the community. The GR partnership was initiated by community members to build pathways to the university and workforce for youth through agriculture, food systems, and natural resource sciences. GR was built on the belief that the urban community is full of cultural assets and has rich skills and experiences in urban growing and food systems, yet can be supported by university partners providing additional knowledge, skills, and resources in agriculture and youth development.

The GR summer program is an urban agricultural and environmental internship program for marginalized youth aged 14-15 years. The term marginalized youth references youth who are systemically disenfranchised and/or treated as outsiders. In GR, this included youth who were marginalized based on their racial/ethnic identity, immigrant identity, religious identity, gender identity, and socioeconomic status. This study took place in the third year of program operation. During that year, 36 youth participated in the nine-week summer program. Youth worked from Monday through Thursday, from 9:00 a.m. to 2:00 p.m., for a total of 20 hours a week. They were paid by the city at an hourly rate of $\$ 11.30$.

Each group of six youth was paired with one community mentor and one undergraduate mentor, and each group was responsible for 2-3 community gardens. These intergenerational garden groups spent the summer growing and caring for gardens; intentionally developing career skills; and learning about topics related to agriculture and environmental sciences contextualized within work experience. While much of the learning was organically woven within their work, youth also participated in a series of workshops on topics related to career development, culture, identity, and agriculture and environmental systems. They also visited the local university, community colleges, and trade schools, and they engaged in discussions with speakers in environmental and food systems fields.

\section{Methodology}

This study employed an explanatory, single, embedded case design. The single case was Grounding Roots and the unit of analysis was the garden group. Case study methodology offers local, ecological validity and the unraveling of meaning in context (Yin, 2017). Specifically, an explanatory case study allowed for the generation of descriptions and explanations of the ways in which learning happened within this alternative space.

\section{Participants}

Four of six garden groups were selected for this study because they had the most complete data sets. Participants are introduced with pseudonyms in the cross-case findings. This research secured the protection of all human subjects.

\section{Data Collection and Analysis}

The experiences of each group were analyzed from multiple perspectives - youth interns, undergraduate mentors, community mentors. The primary data sources utilized were interviews. Youth interns, undergraduate mentors, and community mentors were interviewed using semi-structured protocols. Interviews focused on participants' learning experiences, experiences in their communities, growth, and challenges. Phenomenological approaches were used to create the interview protocols (Merriam \& Tisdell, 2015), with the purpose of illuminating how participants experienced their summer internship experiences and garden group communities. Example interview questions/prompts included "Tell me about a typical day in your garden group" and "What did you learn from working with your peers over the summer?" 
Interviews were transcribed by the first author and analysis was guided by grounded theory approaches, with constant comparative methods, involving iterative cycles of coding and comparison (Charmaz, 2014). An iterative process of deductive coding from theory, and inductive coding from the data, allowed for deep and comprehensive thematic analyses. Deductive coding was rooted in the situated learning theory, communities of practice, and CBE literature. Inductive open coding allowed themes to emerge organically from participants.

\section{Researcher Positionality}

In GR, the first author played several important roles, as a program coordinator, researcher, and community liaison. In these roles, she spent many hours working with all GR partners and stakeholders, as well as designing curriculum and program activities. This multifaceted position afforded a unique perspective to conduct this research. In the past, research has been done on, not with, the community. Given the tense and distrusting history of this community in relation to the university, this positionality of trust and commitment to the community, the youth, and the work (outside of research) is germane.

\section{Findings and Discussion}

First, each garden group is briefly presented for participants and context. Next, cross-case thematic findings are presented and discussed, with data highlighted from select cases.

\section{Garden Groups}

Cricket Ranch Farmers. The Cricket Ranch team (see Table 1) split their time at two garden sites and followed the structure of GR closely, including the entire series of summer workshops. Most workshops were led by Camila. Ms. Betty, who lived in the community and worked in food production for 30 years, shared knowledge in contextualized ways during gardening work times.

Table 1

Cricket Ranch Members

\begin{tabular}{lll}
\hline Role & Name & Identifiers \\
\hline Community mentor & Ms. Betty & White female \\
Undergraduate mentor & Camilla & Ecuadorian-American female \\
Youth & Xia & Hmong female \\
& Ayaan & Somali, male, Muslim \\
& Kylee & White, female \\
& Cai & Hmong, male \\
& Asad & African, male, Muslim \\
& Elijah & African-American, male, autistic \\
\hline
\end{tabular}

Warriors of the Rainbow. The Warriors of the Rainbow team (see Table 2) cared for two gardens and an aquaponics site. This group had a unique partnership with a nearby housing community for people with disabilities, Caring Communities, where they cared for gardens and cooked for residents. The group attended farmers markets occasionally to sell produce and talk with community members about their work. While this group was actively engaged over the summer, they largely designed their own ways of doing things. 
Table 2

Warriors of the Rainbow Members

\begin{tabular}{lll}
\hline Role & Name & Identifiers \\
\hline Community mentor & Ms. June & White, female, Lesbian \\
Undergraduate mentor & Amara & Asian-American Indian, female, bisexual \\
Youth & Kendis & African-American, male \\
& Marques & African-American, male \\
& Deion & African-American, male \\
& Adnan & African, male, Muslim \\
& Umar & African, male, Muslim \\
\hline
\end{tabular}

Inner City Farming Brigade. The Inner City Farming Brigade team (see Table 3) cared for three garden sites. They followed the suggested workshop series closely and reported learning related to career skills, agriculture, and the environment through these workshops. However, mentors adjusted working structures and learning opportunities to incorporate youth voice and choice, as well as movement.

Table 3

Inner City Farming Brigade Members

\begin{tabular}{lll}
\hline Role & Name & Identifiers \\
\hline Community mentor & Joseph & African-American, male \\
Undergraduate mentor & Danielle & White, female \\
Youth & Chee & Hmong-American, female \\
& Durriya & African, Muslim, female \\
& Nia & African-American, female \\
& Nichelle & African-American, female \\
& Saleem & African, male \\
& Muas & Hmong-American, male \\
\hline
\end{tabular}

NOMI Homies. The NOMI Homies team (see Table 4) cared for three gardens. Matthew experienced a serious leg injury at the beginning of the program and was therefore only present for the first week and final three weeks. With Matthew's absence, other community mentors occasionally came to help. The NOMI Homies implemented a mix of the outlined workshops and informal discussions around topics of interest to the youth.

\section{Table 4}

NOMI Homie Members

\begin{tabular}{lll}
\hline Role & Name & Identifiers \\
\hline Community mentor & Matthew & Latino \\
Undergraduate mentor & Emily & White, female, second-year mentor \\
Youth & Talisha & African-American, female \\
& Ashanti & African-American, female \\
& Cua & Asian-American, transgender female \\
& Myshawn & African-American, male \\
& Kamran & African, male, Muslim \\
& Arturo & Hispanic, male \\
\hline
\end{tabular}


Thematic Findings and Discussion

Our case-by-case findings highlighted a number of important elements common to the different groups: (1) Learning to be in a multicultural and multigenerational community; (2) confidence, voice, and leadership development; (3) learning contextualized in an internship grounded in real-world issues; (4) centering issues of equity, diversity, and identity; and (5) assets-based mentoring.

\section{Learning to be in a Multicultural and Multigenerational Community}

Across all groups, learning to be in community was of the utmost importance for both youth and mentors. Rather than focusing on content and performance, groups prioritized building community and trust and engaging with larger communities. Youth spoke to the familial nature of their groups and about taking care of one another and feeling supported. This emphasis on the youth as whole beings supported them to engage in and contribute to learning experiences, and to work hard for the collective cause.

The Inner City Farming Brigade was a racially, ethnically, and linguistically diverse group, and the youth reported that they would not normally hang out together. Over time, youth learned to communicate and work across differences, and they became comfortable with one another. As Durriya explained,

I made friends with all of them. Like, when I'm at school, I'm always friends with the same kind of people 'cause that's the type of people that I attract. And like this job; I was set with these specific five people. ... And so, I got to learn different opinions and different views.

Her reflection shows flexibility and appreciation for diversity of perspectives. Additionally, working in small community groups supported youth in building collaboration and communication skills, which many youth spoke of as a challenging. Durriya continued:

I learned that communication is a lot harder when it's people who are, like, more diverse. 'Cause its like I can; I can, like, turn on my really polite White-sounding voice and everything and, like, be friendly with all of my classmates. But it's different 'cause it's like I hear them talking and then I'm like, what? You talk like me? Like I can talk like I do with you. Like it's just, it was new and it was easy and challenging at the same time.

For the Warriors of the Rainbow, establishing relationship and building trust was foundational. Marques shared, "When I came here, I'm, like, I'm not going to be friends with nobody in this group. And then everybody was cool. 'Cause I ain't know nobody. But we actually became good friends."

The group became a family, taking care of each other, and understanding each other's needs. Ms. June reflected on this process:

Well, I think one of the skills is, you know, figuring out how to work as a team. I think listening to each other as a skill. I think finding a way to support each other. ... And I also think there's a way in which they figured out how to do democracy with each other. You know, how to say, we need to figure that one out.

Scholars have long argued for the importance of community and relationship building as the foundation of learning (e.g., Lave \& Wenger, 1991). Based on extensive work related to CBE, Smith and Sobel (2014) wrote:

Children are drawn to the experience of social membership and participation, not by being removed from their communities, but by being immersed in the world of adults. ... Children are motivated to master new knowledge and skills because doing so allows them to display their competence and make contributions to the lives of those they love and respect. (p. 41)

They further asserted the need to "prepare the young for the forms of collaboration, problem-solving, social commitment, and imagination required to live not merely as individuals, but as members of communities" (p. 101). 
Many youth specifically spoke to the value of having adult mentors, of varying identities, who provided a variety of wisdom and guidance. For example, Deion (Warriors of the Rainbow) explained:

Ms. June, I like me and her relationship 'cause she tries to help anybody she can, even though she's not as young as she looks. And she has a lot of wisdom. I like people who has wisdom 'cause I get to know more. And then like Amara - she's young, she's still understanding more and like they mix well; they, well, it's like that young and the old mixed together. So, you're learning from both perspectives, from Ms. June and Amara.

Cua (NOMI Homies) also spoke about the ways she learned and benefited from each of her mentors. She shared:

They are some of the best people to work with, because they are understanding. Matthew, he will teach you a lot of stuff 'cause he always talks about gardening and community work. ... And, with Emily, she's cool sometimes, funny, and very understanding. Matthew always talks about what certain fruits and vegetables will do for your body. From Emily, more so how to plant. I feel the stuff that I learned from her is like more garden work. Like, she don't really go outside the box. So, it's nice to have both of them.

The power of youth learning to work productively and harmoniously across differences cannot be underestimated. In our experience, this is a skill that needs to be intentionally built, as it does not happen naturally, perhaps because of implicit biases we all possess. Youth began their summers thinking they would never get along with others in their groups. With structured and intentional emphasis on community building, they broke down previously held stereotypes and biases and were grateful for the opportunity to work with people different from themselves.

Mentors intentionally leveraged the diversity of experiences, knowledge, and skills that members brought to the group as a foundation for rich and meaningful learning experiences. Youth were able to learn about cultures, identities, histories, and realities outside their own lived experiences. With time, youth grew to recognize the diversity of their peers and mentors as a learning and growing experience. As previous scholars have argued (Smith \& Sobel, 2014), social aspects of learning, like community building, form the critical foundation for all other learning to take place. Lave (1996) asserted that learning is not a process of knowledge acquisition, but instead a process of becoming a member of a community. We agree, and we further highlight the value of community building across diverse individuals and groups - multiculturally and intergenerationally.

\section{Confidence, Voice, and Leadership Identity Development}

Feeling respected and that they mattered in their garden groups aided youth in developing their own voices, confidence, and sense of leadership. Many of the youth came into their internship with selfdoubt-some because they had been silenced in most educational environments and others because of repeated deficit-oriented, punitive experiences.

In NOMI Homies, the youth remarked about opportunities for growth in leadership, confidence, and exercising their voices. Myshawn reflected:

I understand myself better as a leader-like how much power my voice actually has. 'Cuz I've been having people tell me, like, every day, like how much I can change the world. And, I see it. Well, I tell people all the time that I can do it, and they listen and follow me, and think I'm, like, actually a good person.

This self-belief is so powerful, particularly coming from a young man who had repeatedly experienced punitive and deficit-oriented approaches. Initially, Myshawn struggled with defiance and distracted the group. However, with support from mentors and peers, he learned to use his leadership and charisma to positively influence his group. Kamran shared: 
This internship helped me understand myself better by knowing that I can talk more to people and knowing that I have a creative mind. ... I don't know why or how, but I get inspired a lot from the gardens.

These young men's reflections show an explicit recognition of their assets, and how the community space helped with this recognition.

Others spoke specifically to the leadership skills they built. Ashanti reflected on this growth:

There was a bunch of times when we will need someone to take the action and be a leader and stuff. And I've seen that about from everyone in this group basically become a leader at some times, some point of the day, and just, like, take charge and tell others, like, what to do. We all lead in different ways.

Her response shows a depth of understanding of leadership and how it can take many different forms. This understanding opened her up to seeing herself as leader-something she had not seen in herself before, given her quiet and shy disposition.

The Warriors of the Rainbow mentors took an explicit leadership-oriented approach. Their boys were highly energetic and often vocally oppositional to doing their work. The mentors leveraged these qualities to channel the boys into leadership roles and consistently affirmed moments of leadership. The youth began to see themselves as leaders in different ways. Deion explained: "Ms. June, she called all of us leaders. That's all she talks about is leaders and healthiness. We say something right; she'll be, that's the leader. ... People feel good about themselves and we all said that's the leader." Deion, who had never previously thought of himself as a leader, began to recognize his leadership skills, doing the right thing, and stepping up to do work when no one else would.

The Inner City Farming Brigade mentors supported youth in self-directed work and choice in the gardens. In response, the youth demonstrated growth in confidence and leadership. Durriya voiced: "I learned that I can do more than I thought I could and I'm more capable of doing things that I've never done before." Similarly, Muas reflected: "My confidence has grown. ... I speak up more and I don't hesitate. It feels like I'm invincible." As youth developed confidence, they opened up more with contributions to discussions and problem-solving. Danielle shared:

The confidence level on all my youth increased, and the ability to speak their mind in a small group gives me hope that they'll, like, be able to speak their mind in a bigger group ... being more able to communicate to me what they need, which I think is the most important skill, especially for a future job. They were able to be, like, this is what we need to be successful kind of thing ... to have them have some agency over that is amazing.

In the garden groups, leadership and decision-making were distributed so that youth could develop a sense of choice, voice, and agency. Youth spoke of feeling that they could tackle anything that came their way; of being change agents in their futures; and of being further involved in local and global issues impacting their lives. Valuing youth voices can shift the power dynamics of who and what count as important and knowledgeable. Garden groups formed dialogical learning communities of practice, coming together to construct knowledge and meaning, allowing youth to move from the periphery to the center of the learning community as leaders (Lave \& Wenger, 1991). Thus, traditional hierarchies of teachers as the knowledge givers and students as the knowledge receivers were broken down (Freire, 1970). Findings parallel those by Calabrese Barton and Tan (2010), who also found the horizontal nature of their CBE program supported youth to position themselves with agency as community experts. Leadership, confidence, and voice are especially important for youth of color, whose valuable perspectives are often left out of conversations and decisions important to their lives and communities.

\section{Learning Contextualized in an Internship Grounded in Real-World Issues}

Across all groups, youth spoke about ways in which their learning was connected to meaningful things, like their internship work, their community, and global issues. Youth spoke about learning skills, content, 
and dispositions simultaneously, within the real-world contexts of gardening, climate change, regenerative practices, and food systems. On a basic level, this learning is hands-on, connecting the mind and body. It is experiential and problem-based learning. On a deeper level, such learning has personal meaning and allows youth to contribute to their world as citizens and stewards.

The Cricket Ranch Farmers developed love of nature, working with their hands, and problem-solving in the natural environment. Mentors and youth spoke of hands-on learning. For example, Asad noted: "I mean here you use your hands and bodies and minds together, and at school you use pencils, uh, computers and boards." Camila shared the following perspective on her group's learning experiences:

Definitely it's a lot of outdoor time that they're not getting in a normal classroom, which I think is important because fresh air and they're not trapped and they're not just sitting in one place. So, they have the freedom to be active. And, it's all on an understanding level and it's on a level of making people feel comfortable, which isn't always the same in school. Every day for them is a learning moment in some regard. ... They talk to me about their school or learning about other people's schools or learning about each other and the garden and how the world works or how their community is.

Camila's reflection speaks to the significance of the open and inclusive nature of the garden learning environment and small-group learning. She described how learning emerges from garden work or conversations in community. Through this type of learning, youth came alive with curiosity and love for nature's gifts. Like Lave (1996), we challenge the assumption that formal teaching is necessary. Learning can occur from being in community and doing the work of community together.

The Warriors of the Rainbow developed connections to their community through gardening. Marques relayed his favorite memory: "Probably Caring Communities ... Just like meeting people ... they got a lot of gardens and it's like set up different because most of the people are in wheelchairs. ... It was good to give to that." The group also connected with community members around their other gardens, through interest in and sharing about community gardening.

Deion reflected on the contagious nature of getting out and greening the community. He said:

When we work, people will see us and, like, they'll just see that we are doing work sometimes. I remember we was working outside one day, and this man had walked past. He was, like, can you guys keep doing what you're doing? And it's, and they put a smile on his face 'cause, yeah, 'cause we was like pulling out weeds and planting and stuff. And I think if people see a lot of plants, they'll, like, see that people try to make better for the community so they'll try to do the same.

So often, work in school has no significance, making it hard for youth to feel motivated to work or retain information. In a performance-driven educational culture, youth quickly determine that the purpose of learning is merely to retain information to perform on tests to continue through the system. Rarely do they have opportunities to connect with learning in a personal way or to see its value to their lives and communities. Rarely do they have opportunities to contribute. Young people need to feel valued and valuable. They learn by doing work that contributes to the construction and reconstruction of their communities (Lave \& Wenger, 1991). In Smith and Sobel's (2014) words, "Children everywhere need to be prepared to become collaborators in the creation of communities where economic, social and political practices enhance the welfare of human inhabitants and the integrity of natural systems that support them" (p. 40). Like Calabrese Barton and Tan (2010), we found that youth's desire to learn was grounded in connections to their life experiences and communities. We also found particular value in purposeful work-work that actually contributes and has authentic recipients (Buxton, 2010). Our participants identified many purposes for their work: to green the community; to provide healthy food for the community; to regenerate the environment through organic practices; and to educate and inspire community members to garden and eat healthy. 


\section{Centering Issues of Equity, Diversity, and Identity}

For our youth participants, real-world issues of identity, equity, diversity, and race were particularly important. In three of the four groups, young people regularly initiated discussions around these issues. They talked about over-policing and police brutality in their communities; violence on their streets; gang pressure; disengagement and inequitable punishment at their schools; and disproportionate effects of climate change on people of color in urban communities. Group members shared and compared histories, lived experiences, and perspectives from their unique layers of identity.

The Warriors of the Rainbow often discussed these issues through storytelling. They loved to tell and listen to life stories and experiences from one another. Often these stories were prompted by curiosity and questioning from the young men. Ms. June reflected:

All of those things, where you told a story about something or other, were moments of people connecting. I had been in a street fight, so I sort of explained that to the kids as one of my truths ... dialogue and stories, and that's what I mean. ... T me, that's part of the relationship-building stuff. Kids really wanna know you ... 'cause you're really recreating a family group and you don't recreate a family group on "How are you? I'm fine."

Ms. June's reflection speaks to the power of sharing to build relationships and trust, which sets the foundation for learning. Many stories centered on issues of justice, race, gender, sexuality, and class. The group learned a lot from the diversity of one another's anecdotal experiences-from being queer to immigrating to the U.S. to growing up Black in America.

The Inner City Farming Brigade youth worked hard to connect with and reclaim their neighborhood community. The mentors in the group led intentional conversations about reclaiming their community. Durriya shared her conversation with one of the cooking mentors:

She was telling us, because me and Nia used to live on [street] and Nia was, like, Oh, I don't like [street]; it's scary. And Ms. Mary told us: what you hear in the news and, like, what you hear about people talking about your community is what they're labeling your community. But the only person that can really label something for yourself is yourself. It's s just, like, if that's s what you hear in the news and if someone says, oh, [street] is the most dangerous place [here], then you are letting other people label that for yourselves. And so you're supposed to label it for yourself. Like, you're supposed to be, like, "I feel welcome here; I feel this way about this place," instead of letting other people ...

Through community gardening, the group spent time contributing to the beauty of their community, connecting with neighbors, and welcoming people into the garden. Through this process, combined with intentional conversation, the youth began to center the assets of their community. The group even had the opportunity to help tell their own stories and realities to the local news station and newspaper.

For the NOMI Homies, the diversity of their group was important to their learning. Youth had intimate conversations around race, gender, and sexuality, and about how these layers of identities impacted their experiences of the world. Although Matthew was gone for much of the summer, he led valuable discussions around issues of race and justice while he was there. He led conversations around the power of being Black and the group visited a related exhibit at the local art museum. Youth also initiated these conversations and became extremely open and vulnerable with one another. Emily reflected on a particularly memorable talk:

All of a sudden, it organically went to them talking about how they felt incredibly safe with me in a way that, like, they hadn't really experienced. And they were talking about very personal things that were, like, incredibly difficult with identity, growing up, what you do with your life. Um, gender and, and then basically, like ... I think that was, like, one of the most beautiful times in this whole summer. ... I mean it was just a whole circle of such honesty and then Cua, like, just like came out to us. ... She just was, like, yup, yup, this is who I am, this is how I feel. And then talking about how she felt being misgendered. ... And they wanted to just keep talking, even 
though it was two o'clock. ... To be authentic with them in a way that's, like, it just broke down so many barriers for, I think, all of them.

So many of our youth grow up in a society that devalues and even demonizes multiple layers of their identity. This impacts their lived experiences at a critical point in their identity development, and formal education does not provide space to process these issues. We found that providing youth with space to explore these issues also supported their learning and career development in important ways. Like scholars before us, we argue that elements of identity and sociocultural issues have an important role in learning (Ladson-Billings, 2014; Nasir et al., 2006).

\section{Assets-Based Mentoring Approach}

In all of the groups, mentors saw their youth as valuable contributors in work and learning. They regularly affirmed the youth for their strengths and contributions and turned challenges into opportunities. For example, the Warriors of the Rainbow mentors quickly discovered that the programmatic structures did not work well for their group of young men. Initially, four of the boys wanted nothing to do with plants and dirt; they came late and left early. The mentors chose to work with them in a metered approach to encourage professional growth, opting to hold intentional conversations around infractions. They showed flexibility and understanding in expectations, rather than take the punitive approach youth experienced in formal school settings. Ms. June reasoned her approach:

My group - it's pretty clear to me that some of those kids probably, they came in with a hunk of trauma history, however you want to name it. They've probably had an IEP [Individualized Education Plan] someplace or other. It's sort of is, like, well, if you just kick them out, what does that do? You know, it just teaches them that they're a failure all over again, and I'm sure that they've had that lesson many times. The world is going to give up on them over and over again. And so, yeah, what was the point of that?

Kendis was particularly responsive to this assets-based approach. He showed improvement throughout the summer, although he may not have left the program "job ready" in a traditional sense. With support, he used his musical skills to produce a garden rap with Marques. Using community connections, they were able to record and distribute a high-quality music video. At the end-of-year ceremony, he used his charisma on the microphone to engage the audience and manage transitions. Ms. June reflected on working with the young man:

There was a time with Kendis early on where we were trying to plant and he was being distracted. And we just, and I sort of decided that I wasn't going to get angry and all I was going to do was keep bringing him back to this is the place where he needed to be. ... I mean, I perceived him to be plugged into the universe and he is hearing music, having creative thoughts. That universe is just flowing through him all the time. And so, if you want him to do this particular thing, then you have to get him collected to that spot.

Through this asset-based approach, Kendis became aware of his own assets. At the end of the summer, when asked what he learned, Kendis reported: "I'm a caring person" and "I know to help others, even when they say that they don't need help." He also said, of others: "I want them to know that I can do things that you didn't know I could do."

In NOMI Homies, Emily also worked to turn challenges into assets. She helped Myshawn to channel his apparent defiance into motivational speech and management of garden tasks. She discovered that Arturo, who had been slipping in work ethic, loved clipping the plants for optimal health and presentation. She supported him in taking leadership of the beautification of their garden sites. Both Myshawn and Arturo became increasingly engaged and on task. Emily consistently reflected on the assets of the youth: 
What they really know is how to be kind to each other. And they knew different ways of making a group comfortable, if that makes sense. Like, Arturo, like, knew that, like, it made the day more enjoyable when he was sarcastic and funny. And so that was the knowledge he brought. ... Like, Cua knew that I'm alone a lot of the time. So she knew that, communication-wise, that she needed to step up. So, she would be like a peer that is making Talisha do more.

The mentors saw the diversity in identities and experience of youth as an asset, rather than a barrier. They saw energy and curiosity as an asset to build from, rather than a challenge and distraction to constrain. In response, youth began to recognize and express their own assets. For example, Ayaan (Cricket Ranch Farmers) explained her growth in confidence and affirming her strengths: "I used to, like, doubt myself. If someone say, oh tell us some good things about you, I would not say anything because I didn't know. But, right now, I would say that I'm work harded. I'm respect."

In our study, we found that the assets-based mentoring approach spread to the young people. Through spending time with mentors who honored their strengths and contributions, youth began to more readily recognize their own assets, seeing themselves as leaders, as creative, as problem-solvers, and as kind and giving people. The youth also began to recognize the assets in their community, where they had previously seen deficits and danger, as portrayed by outsiders and the media. They began to see the bounty of gardens, parks, and greenery in their neighborhoods. They began to note the close-knit and neighborly nature of their community, where neighbors regularly asked them what they were up to, and looked to learn from them. These findings are supported by literature that asserts that

Place- and community-based education alerts young people to their own capacities, the assets and needs of their communities, and the importance of their willingness to become involved in the shaping of both individual and collective responses to the demands of the future (Smith \& Sobel, p. 41).

\section{Conclusions and Implications}

While our study took place in a community-based, out-of-school learning environment, our research findings have implications for both in- and out-of-school settings. First, we highlight the holistic educational opportunities found in connecting learning to young people's communities and lives, particularly for youth of marginalized identities. The community-based nature of the GR internship program supported youth in holistic learning and identity development. Holistic learning spanned learning gardening and career skills and learning to be in community and to connect with the greater community. Identity development included the youth recognizing their assets, building confidence, and identifying as leaders and change agents. CBE opportunities can be supported through out-of-school programming in the community and can be creatively designed in schools through connecting class projects to community-based issues and involving community stakeholders. For example, teachers could support their students in identifying problems that need addressing within their communities, and then connect with community members and local businesses to generate ideas and problem-solving approaches.

Second, our work brings attention to the value of intergenerational mentoring. Youth and mentors alike commented on the power of reciprocally learning from the different experiences, perspectives, skills, and knowledge of their peers, near peers, elders, and youngers. In modern times, people so rarely have the opportunity to work with individuals outside their immediate generation. Our study revealed the value of this work for knowledge exchange, idea generation, and problem-solving, all critical in tackling current and future grand challenges. Intergenerational mentoring can be fostered through connections with local communities, colleges, businesses, and workspaces. Schools can partner with local colleges, businesses, and community mentors to bring mentors of different fields and ages into the classroom to provide multigenerational mentorship. Youth can be further supported through internships during the school year and the summer, and provided with academic credit and/or financial compensation for their work. 
Third, our study illuminates the value of racial, ethnic, gender, and sexuality diversity in learning communities. Across the board, youth spoke about the value of working with individuals whom they would never have associated with in their schools. Adults commented on the value of diversity in identities to discussions and learning experiences. This finding highlights the necessity of diverse groupings within classrooms, on all measures of diversity present. For example, classroom small groups can be intentionally designed to represent diverse racial/ethnic, gender, religious, ability, and socioeconomic identities and to place young people with people they don't regularly interact with.

Fourth, our work brings attention to learning opportunities through internships, particularly for youth of marginalized identities. Many of the youth in our study expressed a disconnect between school learning and their lives. In their GR internships, they found value and meaning, contributing to a purpose beyond themselves, and having a real impact on their local community. We found that learning experiences embedded within their job experiences - that arose organically, given the nature of the work-were met with more interest and engagement. This finding has significance for expanding work-based learning opportunities for youth in both in- and out-of-school educational environments. This requires creative partnership building and recognition of youth as responsible and capable citizens.

In conclusion, we advocate that youth have opportunities to connect with their communities and realworld work through community-based education and work-based learning in and out of schools. In this work, we advocate the generation of multigenerational and diverse communities of practice, where members can engage in mentorship, problem-solving, knowledge exchange, and creation of joint meaning together.

\section{Limitations and Future Directions}

This research explored the experiences of the garden groups of Grounding Roots, particularly the impact on the young people, using qualitative methodologies. While qualitative data sources are invaluable to providing depth in meaning in context, those methods limit the scope of the research. Using both qualitative and quantitative methodologies across a greater number of participants could also provide greater insight into the impact of community-based internship education for youth.

While this study focused on CBE in an out-of-school setting, more research on the role of CBE in formal settings is needed. Unlike out-of-school education, in-school education is accessible to all. Therefore, more resources and research attention should be brought to connecting schools and communities in creating real and meaningful learning opportunities for our young people. Furthermore, as work-based learning opportunities expand in schools, research is needed to highlight the opportunities in this mode of experiential learning.

\section{References}

Baldridge, B. (2014). Relocating the deficit: Reimagining Black youth in neoliberal times. American Educational Research Journal, 51, 440-472. https://doi.org/10.3102/0002831214532514

Baldridge, B. J., Beck, N., Medina, J. C., \& Reeves, M. A. (2017). Toward a new understanding of community-based education: The role of community-based educational spaces in disrupting inequality for minoritized youth. Review of Research in Education, 41(1), 381-402. https://doi.org/10.3102/0091732X16688622

Buxton, C. A. (2010). Social problem solving through science: An approach to critical, place-based, science teaching and learning. Equity \& Excellence in Education, 43(1), 120-135. https://doi.org/10.1080/10665680903408932

Calabrese Barton, A. C., \& Tan, E. (2010). We be burnin'!: Agency, identity, and science learning. The Journal of the Learning Sciences, 19(2), 187-229. https://doi.org/10.1080/10508400903530044

Charmaz, K. (2014). Constructing grounded theory. SAGE Publications.

Dewey, J. (1938). Experience and education. Macmillan.

Freire, P. (1970). Pedagogy of the oppressed. Bloomsbury Publishing. 
Ginwright, S., \& Cammarota, J. (2007). Youth activism in the urban community: Learning critical civic praxis within community organizations. International Journal of Qualitative Studies, 20, 693-710. https://doi.org/10.1080/09518390701630833

Gruenewald, D. (2003). The best of both worlds: A critical pedagogy of place. Educational Researcher, 32(4), 3-12. https://doi.org/10.3102/0013189X032004003

Kwon, S. A. (2014). Uncivil youth: Race, activism, and affirmative governmentality. Duke University Press.

Ladson-Billings, G. (2014). Culturally relevant pedagogy 2.0: aka. the remix. Harvard Educational Review, 81(1), 74-84. https://doi.org/10.17763/haer.84.1.p2rj131485484751

Lave, J. (1996). Teaching, as learning, in practice. Mind, culture, and activity, 3(3), 149- 164.

Lave, J., \& Wenger, E. (1991). Situated learning: Legitimate peripheral participation. Cambridge University Press.

Melaville, A., Berg, A. C., \& Blank, M. J. (2006). Community-based learning: Engaging students for success and citizenship. Partnerships/Community, 40. https://digitalcommons.unomaha.edu/slcepartnerships/40

Merriam, S. B., \& Tisdell, E. J. (2015). Qualitative research: A guide to design and implementation. John Wiley \& Sons.

Nasir, N. I. S., Rosebery, A. S., Warren, B., \& Lee, C. D. (2006). Learning as a cultural process: Achieving equity through diversity. In R. K. Sawyer (Ed.), The Cambridge Handbook of the Learning Sciences (pp. 489-504). Cambridge University Press.

Nieto, S. (1994). Lessons from students on creating a chance to dream. Harvard Educational Review, 64(4), 392-427. https://doi.org/10.17763/haer.64.4.4846361m306pl670

Paris, D., \& Winn, M. T. (Eds.). (2013). Humanizing research: Decolonizing qualitative inquiry with youth and communities. SAGE Publications.

Putnam, R. T., \& Borko, H. (2000). What do new views of knowledge and thinking have to say about research on teacher learning?. Educational Researcher, 29(1), 4-15. https://doi.org/10.3102/0013189X029001004

Smith, G. A., \& Sobel, D. (2014). Place- and community-based education in schools. Routledge.

Sukarieh, M., \& Tannock, S. (2011). The positivity imperative: A critical look at the 'new' youth development movement. Journal of Youth Studies, 14(6), 675-691. https://doi.org/10.1080/13676261.2011.571663

Yin, R. K. (2017). Case study research and applications: Design and methods. SAGE Publications.

\section{About the Authors}

Illana C. Livstrom is partnership and outreach coordinator in the College of Food, Agriculture and Natural Resource Sciences at the University of Minnesota (Twin Cities, MN, USA).

Gillian H. Roehrig is professor of science education at the University of Minnesota (Twin Cities, MN, USA).

Amy R. Smith is associate professor of agricultural education at the University of Minnesota (Twin Cities, MN, USA).

Correspondence concerning this article should be addressed to Illana C. Livstrom at livst002@umn.edu. 